\title{
(E)-11,13-TETRADECADIENAL: MAJOR SEX PHEROMONE COMPONENT OF THE EASTERN BLACKHEADED BUDWORM, Acleris variana (Fern.) (LEPIDOPTERA: TORTRICIDAE)
}

\author{
GERHARD GRIES, ${ }^{1 *}$ JIANXIONG LI, ${ }^{2}$ REGINE GRIES, \\ WADE W. BOWERS, ${ }^{3}$ RICK J. WEST, ${ }^{3}$ \\ PRIYANTHA D.C. WIMALARATNE, ${ }^{2}$ GRIGORI KHASKIN, ${ }^{2}$ \\ G.G. SKIP KING, ${ }^{2}$ and KEITH N. SLESSOR ${ }^{2}$ \\ 'Centre for Pest Management, Department of Biological Sciences \\ Simon Fraser University \\ Burnaby, British Columbia, V5A is6, Canada \\ 'Department of Chemistry \\ Simon Fraser University \\ Burnaby, British Columbia V5A IS6, Canada \\ ${ }^{3}$ Forestry Canada, Newfoundland \& Labrador Region \\ St. John's, Newfoundland AIC 5X8, Canada
}

(Received March 9, 1993; accepted September 16, 1993)

\begin{abstract}
E)-11,13-Tetradecadienal (E11,13-14:Ald) is the major sex pheromone component of the eastern blackheaded budworm (EBB), Acleris variana (Fern.). The compound was identified in female pheromone gland extracts by coupled gas chromatographic-electroantennographic detection (GCEAD), coupled GC-mass spectrometry in selected ion monitoring mode, and retention index calculations of candidate pheromone components. E11,1314: Ald alone as trap bait was very attractive to male EBB. Addition of the corresponding diene alcohol or acetate or both did not enhance attraction. $(Z)$ $11,13-T e t r a d e c a d i e n a l$ in binary combination with $(E)-11,13-14:$ Ald neither enhanced nor reduced trap catches. Increasing the amounts of pheromone from 0.01 to $10 \mu \mathrm{g}$ increased trap catches, but increase of pheromone quantity above $100 \mu \mathrm{g}$ proportionately reduced attraction. Stabilization of slowly polymerizing $E 11,13-14$ : Ald and development of a sustained, adequate release rate is required for pheromone-based monitoring of EBB populations.
\end{abstract}

Key Words-Lepidoptera, Tortricidae, Acleris variana, sex pheromone, (E)11,13-tetradecadienal.

*To whom correspondence should be addressed. 


\section{INTRODUCTION}

The eastem blackheaded budworm (EBB), Acleris variana (Fem.), is a microlepidopterous defoliator of 20 different coniferous trees, particularly balsam fir, Abies balsamea (L.) Mill; white spruce, Picea glauca (Moench) Voss; black spruce, P. mariana (Mill.); and westem hemlock, Tsuga heterophylla (Raf.) Sarg. (Rose and Lindqvist, 1977). After egg hatching in late May or early June, larvae begin feeding on developing shoots. Pupation occurs in late July to early August and lasts about two weeks. Moths fly in August and September and lay eggs on the lower surface of needles.

A series of outbreaks occurred in Newfoundland, the maritime provinces, and Quebec from 1945 to 1950 . The most recent EBB infestation has been reported in Newfoundland (Clarke and Carew, 1988; Clarke et al., 1989, 1990). This EBB outbreak caused extensive defoliation of 35,000 ha of mature balsam fir and was associated with feeding by the eastem hemlock looper, Lambdina fiscellaria fiscellaria (Guen.). In 1990, defoliation of 89,000 ha was predicted, and the biological insecticide Bacillus thuringiensis was evaluated as a control measure to reduce larval numbers and to protect foliage (West and Carter, 1992).

Methods of estimating EBB density are required to predict damage and measure the effectiveness of control programs. Egg counts, as described for the westem blackheaded budworm (WBB), Acleris gloverana (Walsingham) (Shepherd and Gray, 1990), are conducted, but pheromone-based monitoring with nonsaturating traps would be a more efficient and sensitive method of monitoring EBB populations. We report the identification of the major sex pheromone component of EBB.

\section{METHODS AND MATERIALS}

Laboratory Analysis. EBB pupae were field-collected near St. John's, Newfoundland, and reared to adults at $20^{\circ} \mathrm{C}, 70 \%$ relative humidity, and a photoperiod of 14:10 hr light-dark. Male and female pupae were kept separately in Petri dishes to avoid mating of emergent moths. Maximal attraction of male WBB to female-baited traps $4 \mathrm{hr}$ after sunset (Shepherd, 1979) suggested that pheromone production by female WBB peaked 4-5 hr into the scotophase. Assuming a similar timing of pheromone production in female EBB, abdominal tips of 2- to 3-day-old virgin females were removed 4-5 hr into the scotophase and extracted for $5 \mathrm{~min}$ in hexane. Aliquots of one female equivalent (FE) of pheromone extract were subjected to gas chromatographic-electroantennographic analysis (GC-EAD) (Am et al., 1975), employing a Hewlett Packard 5890A gas chromatograph equipped with a DB-210 coated, fused silica column (30 $\mathrm{m} \times 0.25 \mathrm{~mm}$ ID) (J\&W Scientific, Folsom, Califomia 95630). Coupled 
lett Packard 5985 B equipped with the same column as above) in full scan and selected ion monitoring mode (SIM) was conducted to confirm the presence of candidate pheromone components in gland extracts. For GC-MS-CI-SIM, full scan electron impact spectra of synthetic $(E)$-11,13-tetradecadien-1-ol $(E 11,13-$ 14:OH), (E)-11,13-tetradecadienal (E11,13-14: Ald), and (E)-11,13-tetradecadienyl acetate $(E 11,13-14: O A C)$ at $5 \mathrm{ng}$ each were obtained to select diagnostic ions. In sequence, $200 \mathrm{pg}$ of synthetic compounds, hexane, and an aliquot of 25 female equivalents of pheromone gland extract were analyzed, each time scanning for the diagnostic ions.

Synthesis of E11,13-14:Ald and Z-11,13-14: Ald. Synthesis of E11,1314: Ald and Z11,13-14: Ald were conducted according to methods previously described (Nesbitt et al., 1973; Yamada et al., 1986).

All field-tested compounds were greater than $99 \%$ chemically and geometrically pure. None of the chemical impurities elicited antennal responses in GC-EAD recordings.

Field-Trapping Experiments. Field experiments in 1991 were conducted at Cochran Pond, $3 \mathrm{~km}$ west of St. John's, Newfoundland. Experiments were set up in randomized complete blocks with traps and blocks at least $20 \mathrm{~m}$ apart. Sticky traps (Sandia Die and Cartridge, Albuquerque, New Mexico) were suspended 1-2 m above ground from balsam fir trees and baited with rubber septa (Sigma Chemical Co., St. Louis, Missouri 63178) impregnated with candidate pheromone components in 10-50 $\mu \mathrm{l}$ of hexane (HPLC grade).

The first two-treatment, 10-replicate experiment (August 16-September 26) tested E11,13-14: Ald at $100 \mu \mathrm{g}$ versus unbaited control traps. The second fourtreatment, five-replicate experiment (September 27-October 8) tested E11,1314 : Ald $(100 \mu \mathrm{g})$ alone, in binary combination with either $E 11,13-14: \mathrm{OH}$ or E11,13-14: OAc at a 100 : 1 ratio each, and in ternary combination with $E 11,13-$ $14: \mathrm{OH}$ and $E 11,13-14: \mathrm{OAC}$ at a $100: 1: 1$ ratio. The third five-treatment, fivereplicate experiment (October 1-10) tested E11,13-14: Ald (100 $\mu \mathrm{g})$ alone and in binary combination with $211,13-14:$ Ald at respective ratios of $100: 1,100: 5$, $100: 10$, and $100: 100$. The fourth six-treatment, four-replicate experiment (October 10-22) tested $E 11,13-14:$ Ald $(100 \mu \mathrm{g})$ alone and in binary combination with $E 11,13-14: \mathrm{OH}$ at respective ratios of 100:0.01, 100:0.1, 100:1, $100: 10$, and 100:100. A final eight-treatment, four-replicate experiment in 1991 (October 18-30) tested E11,13-14: Ald at the following doses: 0.01, 0.1, 1, $10,100,1000$, and $10,000 \mu \mathrm{g}$.

In 1992, a two-treatment, 10-replicate experiment tested $10 \mu \mathrm{g}$ of $E 11,13-$ 14: Ald versus virgin female EBB. Experimental insects were reared in the laboratory $\left(20^{\circ} \mathrm{C}, 65 \%\right.$ relative humidity, $14: 10 \mathrm{hr}$ light-dark). Emergent females were individually placed in perforated plastic cups that were attached to the roof of Multipher traps (Biocontrol Services, Ste-Foy, Quebec). 
GrIES ET AL.

RESULTS

GC-EAD analysis of female pheromone gland extracts revealed four compounds that elicited antennal responses by male EBB antennae (Figure 1). Based on retention index (RI) calculations on a DB-210 column, EAD-active compounds 1,2, and 4 were hypothesized to be corresponding alcohol (RI: 1959), aldehyde (RI: 2038), and acetate (RI: 2165). Each compound eluted too late to be a $\mathrm{C}_{14}$-monoene, but too early to be a conjugated, internal $\mathrm{C}_{14}$-diene, unless the conjugated double-bond position was terminal, resulting in a lowering of the retention index. We therefore hypothesized that compounds 1,2 and 4 were E11,13-14:OH, E11,13-14: Ald and E11,13-14:OAC. These synthetic dienes coincided with antennal responses to gland extract on DB-210 and DB-1 columns. Synthetic diene alcohol and acetate $(50 \mathrm{pg})$ and synthetic diene aldehyde $(50 \mathrm{pg})$ elicited good and very good antennal responses, respectively. GC-MSCI-SIM of $25 \mathrm{FE}$ of pheromone extract, monitoring $\mathrm{m} / \mathrm{z} 211(\mathrm{M}+1)$ and $\mathrm{m} / \mathrm{z}$ $193\left(\mathrm{M}+1-\mathrm{H}_{2} \mathrm{O}\right)$ for E11,13-14:OH, $\mathrm{m} / z 209(\mathrm{M}+1)$ and $\mathrm{m} / \mathrm{z} 191(\mathrm{M}$ $\left.+1-\mathrm{H}_{2} \mathrm{O}\right)$ for $E 11,13-14:$ Ald, and $m / z 253(\mathrm{M}+1)$ and $m / z 193(\mathrm{M}+1$ - HOAc) for E11,13-14:OAc, resulted in exact retention time and good ion ratio matches of synthetic and female-produced compounds, except for the diene alcohol, which was not detected by GC-MS-SIM in gland extracts.

Traps baited with E11,13-14: Ald were significantly more attractive than unbaited control traps (Figure 2). Addition of either E11,13-14:OH or E11,1314: OAc or both to E11,13-14: Ald did not enhance attraction. Addition of Z11,13-14: Ald neither enhanced nor reduced attraction to E11,13-14: Ald.

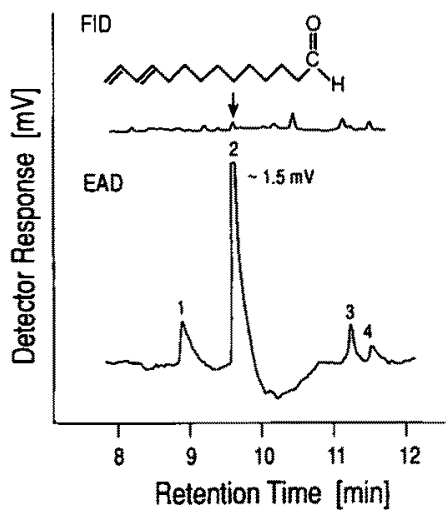

F1G. 1. GC-EAD of female EBB pheromone gland extract. The antennal recording was carried out with a male EBB antenna. $(E)$-11,13-tetradecadienal was present at about 50 pg per female equivalent of pheromone gland extract. DB-210 column $(30 \mathrm{~m} \times 0.25$ mm ID): $1 \mathrm{~min}$ at $100^{\circ} \mathrm{C}, 20^{\circ} \mathrm{C} / \mathrm{min}$ to $180^{\circ} \mathrm{C}, 1^{\circ} \mathrm{C} / \mathrm{min}$ at $220^{\circ} \mathrm{C}$. 
Addition of increasing amounts of $E 11,13-14: \mathrm{OH}$ to $E 11,13-14$ : Ald consistently reduced trap catches (Figure 3), although trap catch reduction was significant only at a 1:1 ratio of aldehyde-alcohol. In the dose-response experiment, increasing the amount of pheromone from $0.01 \mu \mathrm{g}$ to $10 \mu \mathrm{g}$ increased trap catches, but further increase of pheromone quantity $(100-10,000 \mu \mathrm{g})$ proportionately reduced attraction (Figure 4).

\section{DISCUSSION}

In field-trapping experiments, several compounds tested alone or in binary combination at various ratios have been reported to attract Acleris moths; these compounds include: (E)-11-tetradecenal, $(Z)$-11-tetradecenal, $(E)$-11-tetradecenyl acetate, $(Z)$-11-tetradecenyl acetate, and $(E)$-11,13-tetradecadienal

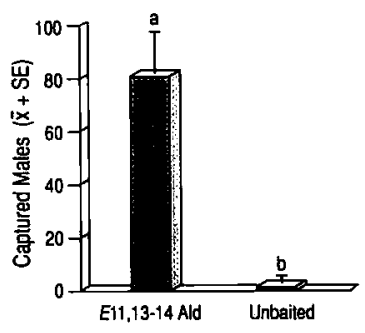

FIG. 2. Captures of EBB males in traps baited with $100 \mu \mathrm{g}$ of E11,13-14: Ald, Cochran Pond, Newfoundland, August 16-September 26, 1991; $N=10$. Bars superscripted by the same letter are not statistically different. ANOVA followed by Duncan's multiple range test on data transformed by $\log _{10}(x+1), P<0.05$.

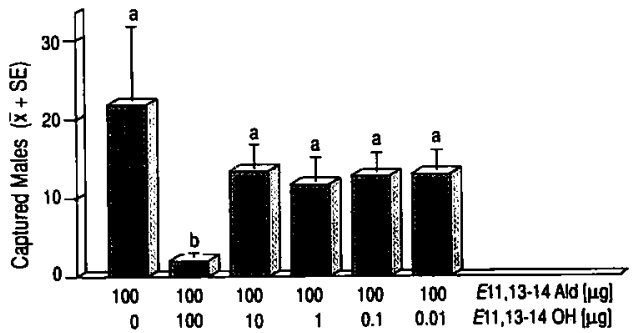

FIG. 3. Captures of EBB males in traps baited with E11,13-14: Ald (100 $\mu \mathrm{g})$ alone and in binary combination with $E 11,13-14: \mathrm{OH}$ at various ratios. Cochran Pond, Newfoundland, October 10-22, 1991; $N=4$. Bars superscripted by the same letter are not significantly different. ANOVA followed by Duncan's multiple range test on data transformed by $\log _{10}(x+1), P<0.05$. 


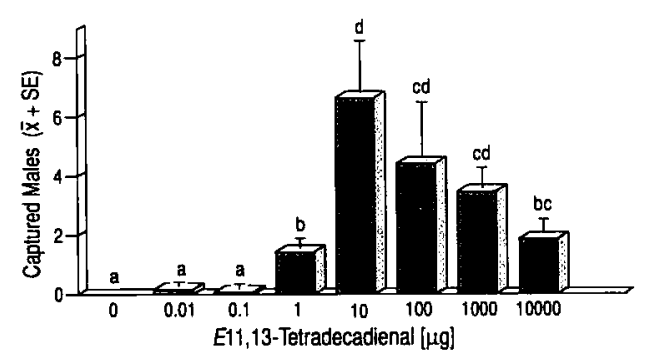

Fig. 4. Captures of male EBB in traps baited with increasing amounts of E11,1314: Ald. Cochran Pond, Newfoundland, October 18-30, 1991: $N=4$. Bars superscripted by the same letter are not significantly different. ANOVA followed by Duncan's multiple range test on data transformed by $\log _{10}(x+1), P<0.05$.

(E11,13-14: Ald) (Mayer and McLaughlin, 1991). In laboratory studies of the sex pheromone of the yellowheaded fireworm, $A$. minuta (Robinson), Schwarz et al. (1983) extracted female ovipositors in heptane and analyzed extracts by GC-MS. Of eight compounds identified in ovipositor extracts, E11,13-14: Ald was the only compound to attract male $A$. minuta in the field. The same diene aldehyde was identified by GC-MS-Cl-SIM in EBB pheromone gland extracts and constitutes the major sex pheromone component in EBB.

Picogram quantities of E11,13-14: Ald elicited strong antennal responses by male EBB antennae, and small amounts of synthetic diene aldehyde (100 $\mu \mathrm{g})$ were exceedingly attractive in field experiments (Figure 2). The corresponding diene acetate was detected in gland extracts by GC-MS-CI-SIM and the corresponding diene alcohol was tentatively identified by retention index calculations of antennal responses. However, neither compound enhanced attraction to $E 11,13-14$ : Ald in field experiments. E11,13-14:OH at a $1: 1$ ratio with $E 11,13-$ 14: Ald even suppressed trap catches (Figure 3). In contrast to other findings (Baker and Cardé, 1979; Sanders and Weatherston, 1976), unnatural, disproportionate ratios of $E$ and $Z$ isomers of the major sex pheromone component neither enhanced nor inhibited attraction of male EBB.

Further experiments were carried out in 1992 to compare attraction of virgin female EBB with that of the most effective synthetic bait, E11,13-14: Ald at 10 $\mu \mathrm{g}$. Because females died within the first very cold night of testing, it remains unknown whether female EBB use a single component sex pheromone as reported for several geometrids and lymantrids (Roelofs et al., 1982: Bestmann et al., 1982; Underhill et al., 1987; Millar et al., 1987; Bierl et al., 1970, 1975). Other as yet unidentified compounds may synergize attraction to $E 11,13-14$ : Ald. Unknown compound 3 (Figure 1), for example, may be behaviorally active, and additional synergistic pheromone components in gland extracts may have occurred in quantities too small to elicit antennal responses in GC-EAD record- 
ings. However, $E 11,13-14$ : Ald alone was as attractive as ovipositor extracts of female $A$. minuta, which contained eight identified components including E11,13-14: Ald (Schwarz et al., 1983). Female A. minuta and possibly also female $A$. variana may indeed use a single component pheromone.

In the dose-response experiment, increasing amounts of pheromone increased trap catches, but pheromone quantities above $100 \mu \mathrm{g}$ proportionately reduced attraction. Use of E11,13-14: Ald for monitoring EBB populations requires determination of a pheromone load optimally attractive throughout the extended flight period of EBB. In addition, a method to stabilize slowly polymerizing $E 11,13-14$ : Ald (Wimalaratne and Slessor, unpublished) needs to be developed.

Acknowledgments-We thank G. Owen for mass spectrometry and S. Burtan, J. Marshall and J. Rowe for field assistance. The research was supported by NSERC, operating grant 3785 to K.N.S.

\section{REFERENCES}

ARN, H., STÄDleR, E., and RAUSCHER, S. 1975. The electroantennographic detector-a selective and sensitive tool in the gas chromatographic analysis of insect pheromones. $Z$. Naturforsch. 30c:722-725.

BAKER, T.C., and CARDÉ, R.T. 1979. Analysis of pheromone-mediated behavior in male Grapholita molesta, the oriental fruit moth (Lepidoptera: Tortricidae). Environ. Entomol. 8:956-968.

Bestmann, H.J., Brosche, T., Koscat7.ky, K.H., Michaelis. K., Platz, H., Roth, K., Suss, J., Vostrovsky, O., and KNAUF, W. 1982. Pheromone-XLII. 1,3,6,9-Nonadecatetraen, das Sexual Pheromone des Frostspanners. Operophtera brumata (Geometridae). Tetrahedron Lett. 23:4007-4010.

Bierl, B.A., Beroza, M., and Colller, C.W, 1970. Potent sex attractant of the gypsy moth: Its isolation, identification and synthesis. Science 170:87.

Bierl, B.A., Beroza, M., Adler, V.E., Kasang, G. Schröter, H., and Schneider, D. 1975. The presence of dispariure, the sex pheromone of the gypsy moth, in the female nun moth. $Z$. Naturforsch. $30 \mathrm{c}: 672$.

Clarke, L.J., and Carew, G.C. 1988. Forest insect and disease conditions in Newfoundland and Labrador in 1988. Newfoundland and Labrador Region. Information Report N-X-268.

Clarke, L.J., and CAREw. G.C. 1990. Forecast of forest insect and disease conditions in Newfoundland and Labrador in 1990. Woody Points 19:1-5.

Clarke, L.J., Sutton, W.L., Banfield, E.L., Stone, D.M., O'Brien, D.S., Pardy, K.E., and CAREW, G.C. 1989. Forest insect and disease conditions in Newfoundland and Labrador in 1989. Newfoundland and Labrador Region. Information Report N-X-275.

Clarke, L.J., Sutton, W.J., Banfield, E.L., Stone, D.M., O'Brien, D.S., Pardy, K.E., Carew, G.C., and RASKE, A.G. 1990. Forest insect and disease conditions in Newfoundland and Labrador in 1990. Newfoundland and Labrador Region. Information Report N-X-283.

MAYER, M.S., and MCLAuGhLIN, J.R. 1991. Handbook of Insect Pheromones and Sex Attractants. CRC Press, Boca Raton, Florida.

Millar, J.G., Underhill, E.W., GibBon, M., and Barton, D. 1987. Sex pheromone components of three species of Semiothisa (Geometridae), $(Z, Z, Z)-3,6,9$-heptatriene and two monoepoxy diene analogs. J. Chem. Ecol. 13:1371-1383.

Nesbitt, B.F., Beevor, P.S., Cole, R.A., Lester, R., and Poppi, R.G. 1973. Synthesis of both 
geometric isorners of the major sex pheromone of the red bollworm moth. Tetrahedron Lett. $00: 4669$.

Roelofs, W.L., Hill, A.S., Linn, C.E., JR., Meinwald, J. Jain, S.L., Herbert, H.J., and SMITH, R.F. 1982. Sex pheromones of the winter moth, a geometrid with unusually low temperature precopulatory response. Science 217:657-659.

ROSE, A.H., and LiNDQuisT, O.H. 1977. Insects of eastern spruces, fir and hemlock. Department of the Environment. Canadian Forestry Service, Forestry Technical Report 23. Ottawa, p. 159.

SANDERS, C.J., and Weatherston, J. 1976. Sex pheromone of the eastem spruce budworm (Lepidoptera: Tortricidae). Optimal blend of trans- and cis-tetradecenal. Can. Entomol. 108:12851290.

Schwarz, M., Klun, J.A., Hart, E.R., Leonhardt, B.A., and Weatherby, J.C. 1983. Female sex pheromone of the yellowheaded fireworm, Acleris minuta (Lepidoptera: Tortricidae). Environ. Entomol. 12:1253-1256.

SHEPHERD, R.F. 1979. Comparison of the daily cycle of aduh behaviour of five forest Lepidoptera form westem Canada and their response to pheromone traps. Mitt. Schweiz. Entomol. Ges. 52:157-168.

SHEPHERD, R.F., and GRAY, T.G. 1990. A sampling system for eggs of the western blackheaded budworm, Acleris goverana (Walsingham) (Lepidoptera: Tortricidae), on westem hemlock, (Tsuga heterophylla (Ref.) Sarg. Can. Entomol. 122:555-562.

Underhill. E.W., Millar, J.G., Ring, R.A., Wong, J.W., Barton, D., and Giblin, M. 1987. Use of a sex attractant and an inhibitor for monitoring winter moth and Bruce spanworm populations. J. Chem. Ecol. 13:1319-1329.

WEST, R.J., and CARTER, J, 1992. Aerial application of Bacillus thuringiensis formulations against eastem blackheaded budworm in Newfoundland in 1990. Forestry Canada Information Report $\mathrm{N}-\mathrm{X}-282$.

Yamada, S., Ohsawa, H., Suzuki, T., and Takayama, H, 1986. Stereoselective synthesis of $(E)-(E, Z)$, and $(E, E)$-conjugated dienes via alkylation of 3-sulfolenes as the key step. $J$. Org. Chem. 51:4934-4940. 